\title{
Oxygen glow discharge cleaning in ASDEX Upgrade
}

\author{
C. Hopf*, V. Rohde, W. Jacob, A. Herrmann, R. Neu, J. Roth, ASDEX Upgrade Team \\ Max-Planck-Institut für Plasmaphysik, EURATOM Association, Boltzmannstr. 2, 85748 Garching, Germany
}

\begin{abstract}
Oxygen-containing glow discharges have been proposed for the removal of redeposited hydrocarbon films in fusion experiments. After the 2004/2005 experimental campaign a 49 hours $\mathrm{He} / \mathrm{O}_{2}$ glow discharge experiment was performed in ASDEX Upgrade. A total of $25 \mathrm{~g}$ of carbon was removed as $\mathrm{CO}$ and $\mathrm{CO}_{2}$. In order to probe erosion in various locations in the vessel 48 well defined laboratory-deposited a-C:H film samples were distributed poloidally and toroidally. In principle, the films were successfully removed on all types of surfaces directly facing the discharge. Additionally, two sets of tungsten-coated tiles were removed from the vessel, one prior to and one after the cleaning discharge. Analysis of films on the tiles revealed that they consisted mainly of boron with only little carbon and deuterium. Neither erosion of these films nor any further reduction of their carbon and deuterium content due to the glow discharge could be detected.
\end{abstract}

PACS numbers: 28.52.Nh, 52.40.Hf, 52.57.Bn, 81.65.Cf

JNM keywords: Carbon, Redeposition, Surface Effects, Tritium

PSI-17 keywords: ASDEX Upgrade, Boron Compounds, Oxygen, Erosion \& Deposition, Tritium

Published in Journal of Nuclear Materials: Received May 2006

Accepted for publication December 2006

Published June 15, 2007

J. Nucl. Mater. 363-365 (2007) 882-887

doi: 10.1016/j.jnucmat.2007.01.108

\section{INTRODUCTION}

For ITER the availability of techniques for detritiation or removal of redeposited hydrocarbons is a mandatory requirement for operation with tritium [1,2]. For ASDEX Upgrade (AUG) the step-by-step move towards an all-tungsten first wall [3-5] makes the removal of redeposited films from previous operation with a mixed tungsten/carbon wall desirable. During the 2004/2005 campaign already $\sim 66 \%$ of the former carbon surfaces had been replaced by tungsten-coated tiles [5]. Among others [6], oxygen containing glow discharges have been proposed as detritiation technique [7, 8] with the advantages of operation at room temperature and of requiring only simple — and mostly already installed-hardware. First tests of the technique in a tokamak environment have been carried out at TFTR [9], TEXTOR [10], and HT-7 [11].

Erosion of carbon materials by oxygen, either thermally, by ion bombardment, or in plasmas was investigated in many works in the literature (for a review see e. g. [12]). Landkammer et al. and Jacob et al. [8, 13] investigated oxygen plasma erosion of amorphous hydrocarbon films $(\mathrm{a}-\mathrm{C}: \mathrm{H})$. They showed that oxygen plasmas erode a-C:H by a factor of five to ten more effectively than hydrogen or deuterium plasmas. Concerning the underlying mechanism, Landkammer and Jacob came to the conclusion that ions, irrespective of their species, create reactive sites at which neutral oxygen species react chemically to form $\mathrm{CO}, \mathrm{CO}_{2}$, and $\mathrm{H}_{2} \mathrm{O}$. Experiments with simultaneous Ar ion and thermal molecular oxygen bombardment, performed by Vietzke et al. [14] and recently in our laboratory [15], indicate that $\mathrm{O}_{2}$ is the most important of these neutral oxygen species. Although much more

*Email address: Christian.Hopf@ipp.mpg.de reactive than $\mathrm{O}_{2}$, the radicals $\mathrm{O}$ and $\mathrm{O}_{3}$ contribute only little to oxygen plasma erosion, as can be seen when shielding the erosion sample from ion flux. Due to the small concentration of these radicals compared with that of molecular oxygen the synergistic interaction of ions and $\mathrm{O}_{2}$ seems to be the dominant erosion mechanism in typical oxygen plasmas. Without ion bombardment erosion by $\mathrm{O}_{2}$ requires temperatures above $\sim 600-1000 \mathrm{~K}[12,16,17]$ depending on the type of (hydro-) carbon material.

For reasons of stability of a dc glow discharge and for safety considerations mixtures of oxygen and helium are preferred to pure oxygen for the cleaning discharges. We studied the effect of the mixture ratio $R=\left[\mathrm{O}_{2}\right] /\left(\left[\mathrm{O}_{2}\right]+[\mathrm{He}]\right)$ in an ECR plasma with rf-biased sample holder on the erosion rate of a$\mathrm{C}: \mathrm{H}$ films [18]. The erosion rate saturates between $R=0.1$ and 0.2 , because with increasing supply of molecular oxygen erosion becomes limited by the ion-induced creation of reactive sites. As the ion flux density to the wall from a typical dc glow discharge in AUG is roughly a factor of six less than from the ECR discharge, saturation is expected at even lower mixture ratios $R$, however at an accordingly lower rate.

We have studied the erosion of redeposited layers from AUG in laboratory experiments [18]. Complete removal of the layers was demonstrated on collector samples as well as on tiles, which had been removed in 2002 . For the tiles, eroded under AUG-like dc glow discharge conditions, an average removal rate of $1 \times 10^{13} \mathrm{C}$ atoms $\mathrm{cm}^{-2} \mathrm{~s}^{-1}$ was determined.

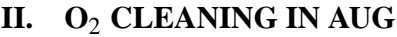

\section{A. Setup and dc glow discharge operation}

ASDEX Upgrade is equipped with four anode rods at the outer wall for DC glow discharges. The whole first wall serves 

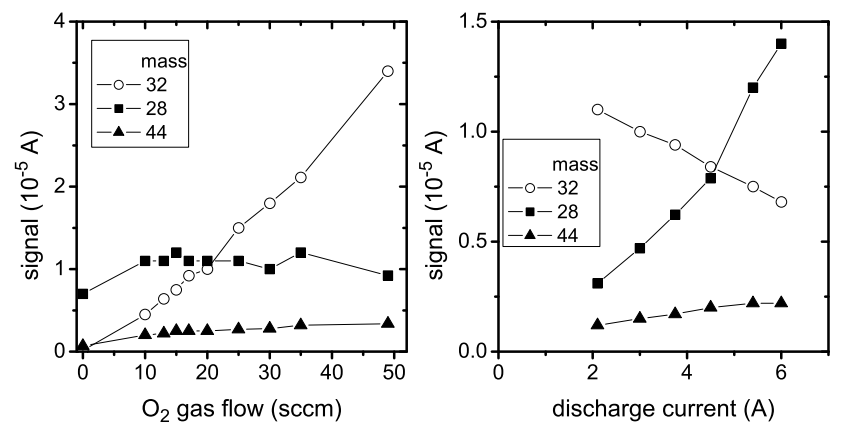

FIG. 1: Quadrupole mass spectrometry signals of masses 28 (contributions of $\mathrm{CO}$ ), 32 (contributions of $\mathrm{O}_{2}$ ), and 44 (contributions of $\mathrm{CO}_{2}$ ) as function of $\mathrm{O}_{2}$ gas flow (a) and discharge current (b).

as cathode. Each anode is driven by a $2 \mathrm{~A}, 2 \mathrm{kV}$ power supply. Unfortunately, due to technical problems only three of the anodes were operational. Typical discharge parameters were: He flow $2440 \mathrm{sccm}, \mathrm{O}_{2}$ flow $49 \mathrm{sccm}$, chamber pressure $6.4 \times 10^{-3}$ mbar, discharge current $3 \times 1.8 \mathrm{~A}$, and discharge voltage $\sim 600 \mathrm{~V}$.

During the 2004/2005 campaign AUG had been operated with deuterium plasmas except for the last 56 shots in order to exchange tritium in the walls. For preparations, i. e. installation of erosion markers and removal of tiles for analysis, the torus was vented and left open for one week. After evacuation of the vessel and pumping over the weekend to a base pressure of $\sim 10^{-5} \mathrm{mbar}$, a pure He glow discharge was ignited. After several hours a few percent of oxygen were admixed. The total duration of the glow discharge with oxygen was 49 hours.

During the whole experiment the discharge was monitored by mass spectrometry. Figure 1 shows the signals of masses 32,28 , and 44 , to which $\mathrm{O}_{2}, \mathrm{CO}$, and $\mathrm{CO}_{2}$ contribute. In Fig. 1a) the oxygen gas flow was varied. The other parameters were as given above. Without oxygen the signal of mass 28 will mainly be due to residual $\mathrm{N}_{2}$. The increase of the signals of masses 28 and 44 when oxygen is admixed was attributed to $\mathrm{CO}$ and $\mathrm{CO}_{2}$ production. Above $10 \mathrm{sccm} \mathrm{O}$ flow the two signals show hardly any further increase. In Fig. 1b) the discharge current was varied while the oxygen flow was constant at $15 \mathrm{sccm}$. The mass 28 and 44 signals increase almost linearly with the current. At the same time the oxygen signal decreases because oxygen is consumed in the erosion process. From these two dependences we conclude that for our typical parameters $\mathrm{CO}$ and $\mathrm{CO}_{2}$ production-in other words carbon erosion-is limited by the discharge current, i. e. the ion flux, not the oxygen concentration.

From the mass spectrometry signals a carbon removal rate of $0.5 \mathrm{~g} / \mathrm{h}$ was derived using literature values for the cracking patterns and relative ionization probabilities of $\mathrm{He}, \mathrm{N}_{2}, \mathrm{O}_{2}$, $\mathrm{CO}$, and $\mathrm{CO}_{2}$, the total pressure measured by a baratron, and the total gas flow. Multiplied by 49 hours discharge time this gives a total of $\sim 25 \mathrm{~g}$ of removed carbon.

The amount of tritium in the exhaust gas, determined by freezing water at a nitrogen trap and measuring its activity, increased by a factor of 30 when admixing oxygen to the discharge, indicating effective hydrogen isotope removal from

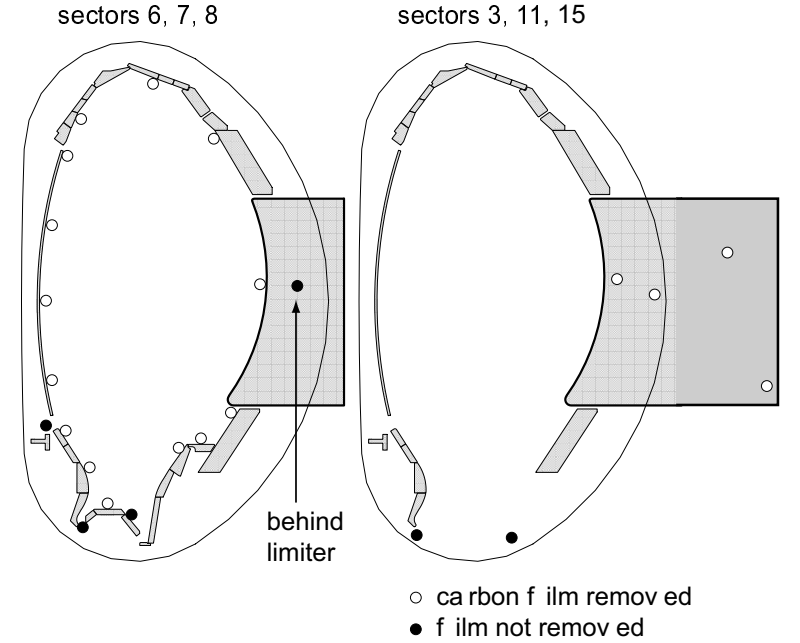

FIG. 2: Poloidally distributed erosion samples. The samples were mounted in various sectors as given above. Open circles indicate that the film was completely eroded, solid circles mean no erosion.

the walls.

\section{B. a-C:H erosion samples}

Erosion was probed by putting hard a-C:H-film samples into various locations in the vessel. The films, plasmadeposited on silicon wafers, were $\sim 350$ or $\sim 200$ nm thick. On some of the sample holders a blank piece of silicon was mounted additionally in order to be able to detect deposition. Before and after the cleaning discharge the samples were measured by ellipsometry.

One set of erosion samples was distributed poloidally as indicated by the circles in Fig. 2. The result turned out to be for the most part binary: Either the film was completely eroded, or all the film was still there. The oxygen glow discharge eroded the films in most places, even in very remote positions in the big ports. Exceptions are the samples in gaps, deep in the divertor, and in other "hidden places". The divertor tiles above the samples at the bottom in the right cross-section had been removed before the cleaning experiment. Still, these samples were not eroded.

Two more sets of erosion samples were distributed toroidally. One sample was put on the horizontal surface at the rim of the outer divertor in each sector except sectors 2 and 11, where these surfaces had been removed. Another sample was put onto the roof baffle in each of sectors 3-10. Again, either the whole film was eroded or the film was not eroded at all, as shown in Fig. 3. For the eroded samples the formation of up to $100 \mathrm{~nm}$ thick silicon oxide layers indicates that the films were eroded long before the end of the discharge.

On top of the $350 \mathrm{~nm}$ a-C:H on the non-eroded samples as well as on some eroded or originally blank Si samples a new layer has formed which is clearly visible in ellipsometry and has a refractive index of $n=1.6$ at a wavelength of $632.8 \mathrm{~nm}$. Furthermore, on some eroded samples an un- 


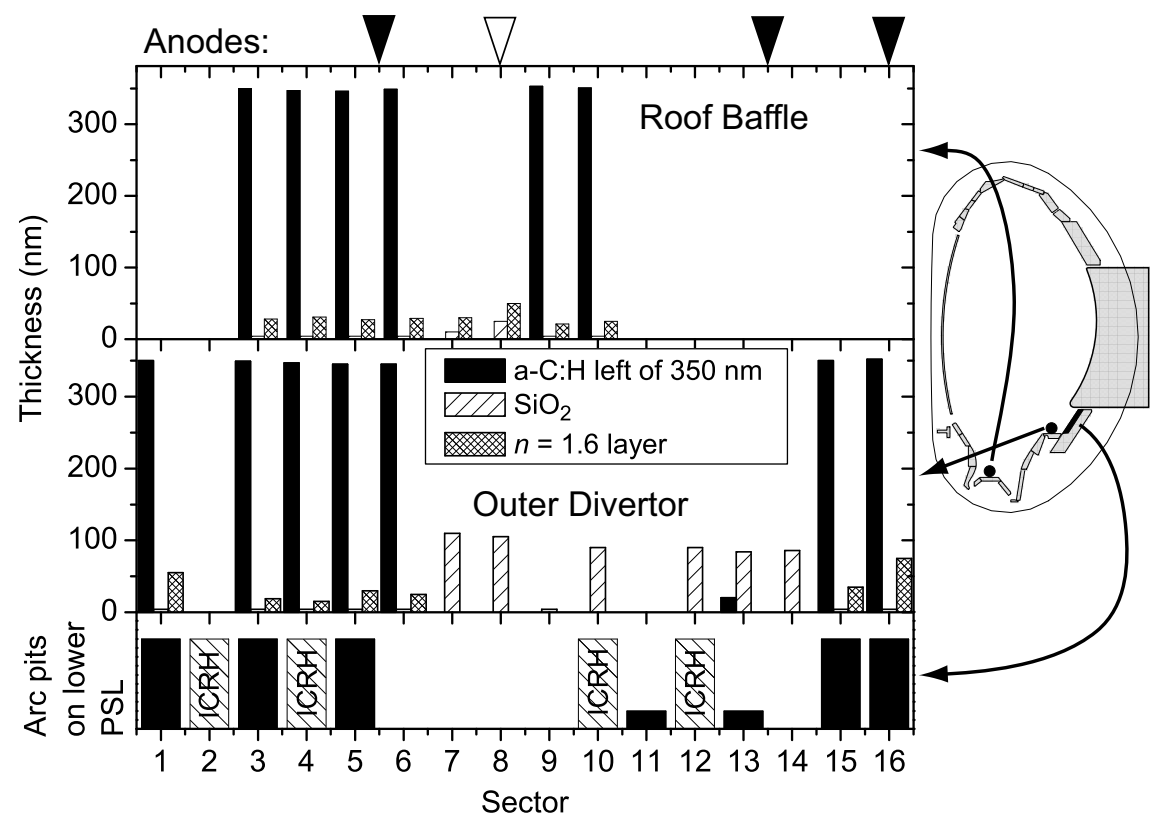

FIG. 3: Toroidally distributed erosion samples. The upper two panels show the samples on the roof baffle and on the rim of the outer divertor. The abscissa shows the number of the sector. The bars indicate the thickness of a-C:H left of the initial $350 \mathrm{~nm}$ (solid), the thickness of $\mathrm{SiO}_{2}$ (hatched), and the thickness of a newly grown layer with a refractive index of $n=1.6$ (crosshatched). At the bottom the appearance of arc traces on the lower-PSL surface (marked in black in the cross-section on the right) is indicated qualitatively (many, few, none) together with the toroidal position of the ICRH antennas. The toroidal positions of the anodes are given by the triangle on top of the figure. The antenna indicated by the open triangle was not operative.

clear result was obtained with ellipsometry, only showing that there is some material on the $\mathrm{Si}$ substrate. The composition of these layers was analyzed by nuclear reaction analysis and Rutherford backscattering with $2.5 \mathrm{MeV}{ }^{3} \mathrm{He}$. The result can be summarized as follows: The layers with $n(633 \mathrm{~nm})=1.6$ are carbon-containing layers $\left(<5 \times 10^{17} \mathrm{~cm}^{-2}\right)$ with negligible amounts of deuterium $\left(<3 \times 10^{15} \mathrm{~cm}^{-2}\right)$, formed possibly due to decomposition and redeposition of carbon-containing erosion products such as $\mathrm{CO}$ and $\mathrm{CO}_{2}$ in the glow discharge. Other major constituents of the deposited material are boron $\left(<1.5 \times 10^{17} \mathrm{~cm}^{-2}\right)$ and oxygen $\left(<1 \times 10^{17} \mathrm{~cm}^{-2}\right)$. Besides, smaller amounts of copper, iron, tungsten, and silver could be detected (all $<3 \times 10^{16} \mathrm{~cm}^{-2}$ ). The latter element most probably comes from silver-coated screws used inside the torus.

Figure 3 shows that the erosion efficiency depends on the toroidal position in the torus; the samples on the roof baffle were eroded everywhere but in sectors 7 and 8 . The samples on the rim of the outer divertor were eroded in one half of the divertor from sector 7 to 14 , but not in the other half. The position of the anodes, which is given on the top of Fig. 3, is not obviously correlated with this pattern.

Concerning this erosion pattern, it has to be mentioned that - in contrast to the routinely glow discharge conditioning during the previous experimental campaign - the discharge never burnt smoothly in our cleaning experiment. Arcs were permanently observed at the walls. After the experiment traces of these little arcs were found on parts of the walls which were coated with well-visible layers. This implies that the electrical conductivity of these layers was very low. The arcs did not develop on conductive surfaces such as clean tungsten. A closer look at the surface of the so-called lower passive stabilizing loop (PSL), to which the divertor-rim samples were very close, revealed that there was a high density of arc pits in the sectors of no erosion and no or almost no such pits in the sectors where the samples had been eroded. The correlation is depicted in the lowest part of Fig. 3. The sectors $2,4,10$, and 12 were excluded from this observation because they contain the ICRH antennas just above the lower PSL. No arcs were found on any of the PSL surfaces in these four sectors, and we believe that this might be a geometrical effect by the antennas which shield the PSL surfaces from ion flux. As explanation for the inefficiency of erosion in the vicinity of arc pits we propose that most of the discharge current in these areas was carried by the arcs and therefore not homogeneously distributed over the wall surfaces. The toroidal asymmetry of erosion efficiency of the glow discharge thus reflects the asymmetry of the distribution of insulating layers on the walls. The origin of the latter asymmetry is, however, not known. The composition of the insulating films is the topic of the following section.

\section{Films on tiles}

A set of tungsten-coated tiles showing obvious deposition on at least a part of their surface was removed prior to the glow discharge and another such set after the discharge. For a before-and-after comparison three pairs of tiles were chosen: inner heat-shield tiles from equal positions in sectors 12 and 13 , neighboring tiles from the inner upper divertor in sec- 


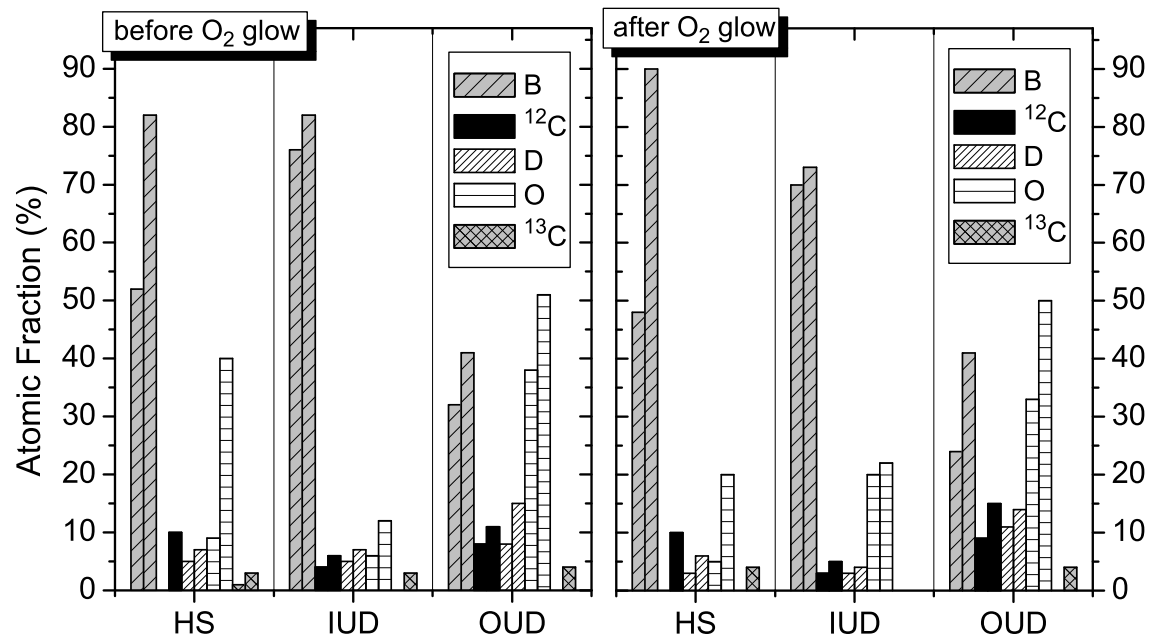

FIG. 4: Composition of the layers on tiles removed before and after $\mathrm{O}_{2}$ cleaning. The origin of the tiles is indicated on the abscissa, HS means inner heat shield, IUD inner upper divertor, and OUD outer upper divertor. For each tile and element the minimum and maximum of the concentrations determined on various measurement spots is given.

tor 12, and neighboring tiles from the outer upper divertor in sector 11 . The layers on the tiles were investigated by ionbeam analysis. Nuclear reaction analysis with $2.5 \mathrm{MeV}{ }^{3} \mathrm{He}$ allowed to detect $\mathrm{D}, \mathrm{B},{ }^{12} \mathrm{C},{ }^{13} \mathrm{C}$, and ${ }^{16} \mathrm{O}$. Absolute values of areal densities were obtained by comparison with calibration targets for each of the mentioned elements. Additionally, where possible, backscattering with $3 \mathrm{MeV}$ protons was evaluated for additional information.

On the investigated tiles total areal densities of deposited material of up to $8 \times 10^{18} \mathrm{~cm}^{-2}$ were found, which, assuming a density of the films of $10^{16}$ atoms per $\mathrm{cm}^{2} \cdot \mathrm{nm}$, correspond to a film thickness of up to $800 \mathrm{~nm}$. In most measurement spots, however, the areal densities were by a factor of two or more smaller.

The composition of the layers before and after the glow discharge is shown in Fig. 4. For each tile and element the minimum and maximum concentration measured in different spots of the tile are shown as neighboring bars. All layers contain a large fraction of up to $80 \%$ of boron from boronization of the machine and up to $50 \%$ of oxygen. Carbon and deuterium were only found with concentrations below $15 \%$. The layers on a tile from the upper part of the inner lower divertor, removed before the glow discharge but not shown in Fig. 4, have similar composition.

Comparing the composition before and after cleaning we find no significant differences. Also, there is no indication for a reduction of the film thickness. We have to conclude that the boron-dominated films prevailing after the 2004/2005 campaign are not susceptible to erosion in an oxygen plasma, either because they did not experience ion bombardment due to their low conductivity or because of their composition. It is known that amorphous hydrogenated boron films (a-B:H) can not be chemically eroded by oxygen because boron oxide $\left(\mathrm{B}_{2} \mathrm{O}_{3}\right)$ is not volatile at normal working temperatures (melting point $450{ }^{\circ} \mathrm{C}$ and boiling point $1860^{\circ} \mathrm{C}$ ). Furthermore, it seems that the oxygen discharge is also not able to preferentially remove carbon from the material mix of the layers. Even no significant reduction of the deuterium content could be detected.

From the different behavior of He glow discharges during the campaign and during the cleaning experiment, prior to which the chamber had been vented, we conclude that the layers have changed due to exposure to air, resulting in a decreased conductivity.

\section{Return to normal plasma operation}

After a four-months opening of the vessel for maintenance the operation of ASDEX Upgrade was restarted. There occurred no problems with the He glow discharges right from the beginning. After the usual conditioning procedure $-72 \mathrm{~h}$ of baking at $150{ }^{\circ} \mathrm{C}, 10 \mathrm{~h} \mathrm{He}$ glow discharge, and boronizationplasma operation was resumed without any hints on increased oxygen content in the plasma.

\section{DISCUSSION AND CONCLUSION}

From the estimation of the total amount of carbon removed from AUG of $25 \mathrm{~g}$ in $49 \mathrm{~h}$ at a discharge current of $5.4 \mathrm{~A}$ we get an average erosion yield of 0.21 eroded $\mathrm{C}$ atoms per incident ion. For comparison, according to TRIM.SP calculations the physical sputtering yields of $\mathrm{He}^{+}$and $\mathrm{O}_{2}^{+}$ions incident on graphite or a-C:H lie between 0.03 and 0.08 for an estimated ion energy of $300 \mathrm{eV}$. However, physical sputtering produces predominantly $\mathrm{C}$ atoms instead of volatile species which are therefore not included in the $25 \mathrm{~g}$ of removed C. Assuming homogeneous erosion, the removed amount corresponds to $\sim 300 \mathrm{~nm}$ of a-C:H everywhere on the walls. However, the boron-dominated layers after the 2004/2005 campaign could not be eroded and no significant change of the carbon concentration could be detected. A possible origin of the re- 
moved carbon are the remaining carbon surfaces $(\sim 34 \%$ of the PFCs), the carbon eroded in the arc pits, and carbon dust in the torus.

It was observed that the boron-dominated layers could not be removed. This raises the general question-which is to be answered for any T-removal technique - which mixed layers are to be expected in ITER and are the techniques also able to erode these or remove $\mathrm{T}$ from them. The ability to erode a-C:D or similar films is no sufficient proof that a specific technique fulfills ITER requirements.

Unfortunately, not many analyses of deposits on inner-heatshield tiles were made in the past $[19,20]$. The different erosion behavior of the redeposited layers on heat shield tiles removed 2002 and 2005, however, implies that carbon redeposition has been decreasing due to the increase of the tungsten coated area over the last years. Analysis of heat shield tiles removed in different years is under way now.

The laboratory experiments as well as the erosion samples in AUG showed that tile gaps and other hidden areas are not sufficiently cleaned by oxygen glow discharges at $300 \mathrm{~K}$. Recent studies [21] indicate, however, that a large fraction of the redeposited carbon and co-deposited tritium will be found in tile gaps. Therefore, one stand-alone technique for $\mathrm{T}$ (and eventually $\mathrm{C}$ ) removal or a combination of techniques has to access these areas, too. This appears to be a strong argument against glow discharge cleaning with oxygen as the sole technique.

\section{Acknowledgement}

The authors thank M. Mayer and K. Krieger for their assistance during ion-beam analysis and T. Härtl for technical assistance during oxygen cleaning at AUG.
[1] G. Federici, C. H. Skinner, and J. N. Brooks et al., Nucl. Fusion 41, 1967 (2001).

[2] R. A. Causey, J. N. Brooks, and G. Federici, Fusion Eng. Des. 61-62, 525 (2002).

[3] R. Neu, K. Asmussen, and S. Deschka et al., J. Nucl. Mater. 241, 678 (1997)

[4] R. Neu, R. Dux, and A. Kallenbach et al., Nucl. Fusion 45, 209 (2005).

[5] R. Neu, V. Bobkov, and R. Dux et al., J. Nucl. Mater. (2007), doi:10.1016/j.jnucmat.2006.12.021.

[6] C. H. Skinner, C. P. Coad, and G. Federici, Physica Scripta T111, 92 (2004).

[7] W. L. Hsu, J. Vac. Sci. Technol. A 7, 1047 (1989).

[8] W. Jacob, B. Landkammer, and C. Wu, J. Nucl. Mater. 266-269, 552 (1999).

[9] D. Mueller, W. Blanchard, and J. Collins et al., J. Nucl. Mater. 241-243, 897 (1997).

[10] M. J. M.J. Rubel, G. De Temmerman, and G. Sergienko et al., J. Nucl. Mater. (2007), doi:10.1016/j.jnucmat.2007.01.107.

[11] J. S. Hu, J. G. Li, and X. M. Wang, J. Nucl. Mater. 350, 9 (2006).
[12] E. Vietzke and A. A. Haasz, in Physical Processes of the Interaction of Fusion Plasmas with Solids, edited by W. O. Hofer and J. Roth (Academic Press, 1996), pp. 135-176.

[13] B. Landkammer, A. von Keudell, and W. Jacob, J. Nucl. Mater. 264, 48 (1999).

[14] E. Vietzke, T. Tanabe, V. Philipps, M. Erdweg, and K. Flaskamp, J. Nucl. Mater. 147, 425 (1987).

[15] C. Hopf, M. Schlüter, and T. Schwarz-Selinger, to be published (2006).

[16] C. Li, C. L. Minh, and T. C. Brown, J. Catal. 178, 275 (1998).

[17] C. Li and T. C. Brown, Carbon 39, 725 (2001).

[18] C. Hopf, W. Jacob, and V. Rohde, to be published (2006).

[19] W. Schneider, D. Hildebrandt, and X. Gong et al., in 28th EPS Conference on Contr. Fusion and Plasma Phys. Funchal, 18-22 June 2001, ECA Vol. 25A (2001), p. 189.

[20] K. Krieger, J. Likonen, and M. Mayer et al., J. Nucl. Mater. 337-339, 10 (2005).

[21] K. Krieger, W. Jacob, and D. Rudakov et al. (2007), doi:10.1016/j.jnucmat.2007.01.155. 